\title{
Neuropsychiatric phenotypes and a distinct constellation of ASD features in $3 q 29$ deletion syndrome: results from the $3 q 29$ registry
}

Rebecca M. Pollak', Melissa M. Murphy², Michael P. Epstein², Michael E. Zwick²,3, Cheryl Klaiman ${ }^{3,4}$, Celine A. Saulnier ${ }^{3}$, the Emory $3 q 29$ Project and Jennifer G. Mulle $2,5,6^{*}$ (D)

\begin{abstract}
Background: The 1.6 Mb 3q29 deletion is associated with neurodevelopmental and psychiatric phenotypes, including increased risk for autism spectrum disorder (ASD) and a 20 to 40-fold increased risk for schizophrenia. However, the phenotypic spectrum of the deletion, particularly with respect to ASD, remains poorly described.

Methods: We ascertained individuals with $3 q 29$ deletion syndrome (3q29Del, "cases," $n=93,58.1 \%$ male) and typically developing controls ( $n=64,51.6 \%$ male) through the $3 q 29$ registry (https://3q29deletion.patientcrossroads. org). Self-report of neuropsychiatric illness was evaluated for 93 cases. Subsets of participants were evaluated with the Social Responsiveness Scale (SRS, $n=48$ cases, 56 controls), Social Communication Questionnaire ( $n=33$ cases, 46 controls), Autism Spectrum Screening Questionnaire ( $n=24$ cases, 35 controls), and Achenbach Behavior Checklists ( $n=48$ cases, 57 controls).

Results: 3q29Del cases report a higher prevalence of autism diagnoses versus the general population (29.0\% vs. $1.47 \%, p<2.2 \mathrm{E}-16)$. Notably, $3 q 29$ deletion confers a greater influence on risk for $\mathrm{ASD}$ in females $(\mathrm{OR}=41.8, p=$ $4.78 \mathrm{E}-05)$ than in males $(\mathrm{OR}=24.6, p=6.06 \mathrm{E}-09)$; this is aligned with the reduced male:female bias from 4:1 in the general population to 2:1 in our study sample. Although $71 \%$ of cases do not report a diagnosis of ASD, there is evidence of significant social disability (3q29Del SRS T-score $=71.8$, control SRS T-score $=45.9, p=2.16 \mathrm{E}-13$ ). Cases also report increased frequency of generalized anxiety disorder compared to controls (28.0\% vs. $6.2 \%, p=0.001)$, which is mirrored by elevated mean scores on the Achenbach diagnostic and statistical manual-oriented sub-scales $(p<0.001)$. Finally, cases show a distinct constellation of ASD features on the SRS as compared to idiopathic ASD, with substantially elevated Restricted Interests and Repetitive Behaviors, but only mild impairment in Social Motivation.

(Continued on next page)
\end{abstract}

\footnotetext{
* Correspondence: jmulle@emory.edu

2Department of Human Genetics, School of Medicine, Emory University,

Atlanta, USA

${ }^{5}$ Department of Epidemiology, Rollins School of Public Health, Emory

University, Atlanta, USA

Full list of author information is available at the end of the article
}

(c) The Author(s). 2019 Open Access This article is distributed under the terms of the Creative Commons Attribution 4.0 International License (http://creativecommons.org/licenses/by/4.0/), which permits unrestricted use, distribution, and reproduction in any medium, provided you give appropriate credit to the original author(s) and the source, provide a link to the Creative Commons license, and indicate if changes were made. The Creative Commons Public Domain Dedication waiver (http://creativecommons.org/publicdomain/zero/1.0/) applies to the data made available in this article, unless otherwise stated. 


\begin{abstract}
(Continued from previous page)
Conclusions: Our sample of 3q29Del is significantly enriched for ASD diagnosis, especially among females, and features of autism may be present even when an ASD diagnosis is not reported. Further, the constellation of ASD features in this population is distinct from idiopathic ASD, with substantially less impaired social motivation. Our study implies that ASD evaluation should be the standard of care for individuals with 3q29Del. From a research perspective, the distinct ASD subtype present in 3q29Del is an ideal entry point for expanding understanding of ASD.
\end{abstract}

Keywords: Autism, Copy number variants, 3q29 deletion, Psychiatric genetics, SRS, Developmental delay, Genomic disorder,

\section{Background}

3 q29 deletion syndrome (3q29Del) is a rare $(\sim 1$ in 30 , 000) $[1,2]$ genomic disorder characterized by a $1.6 \mathrm{Mb}$ typically de novo deletion on chromosome 3 [3-5]. The interval contains 21 distinct protein-coding genes, 3 antisense transcripts, 1 long noncoding RNA, and 1 microRNA. Our understanding of the syndrome phenotype continues to evolve. Initial reports found developmental delay/intellectual disability universal among 3q29 deletion carriers, though some case reports have since identified individuals without cognitive impairment [6]. The 3q29 deletion is associated with a 20 to 40 -fold increased risk for schizophrenia (SZ), with multiple replication studies supporting this association [7-11]. Case reports also indicate other neuropsychiatric phenotypes may exist, including attention-deficit/hyperactivity disorder (ADHD) and bipolar disorder [3, 4, 12-16]. Previous work by our team examining self-report data from 44 individuals with 3q29Del revealed a high prevalence $(\sim 20 \%)$ of generalized anxiety disorder [5]. Further, case reports have long suggested an association with autism spectrum disorder (ASD), and studies with large sample sizes indicate that the 3q29 deletion may confer a 19fold increased risk for ASD $(p=0.001)[17,18]$.

The range of neuropsychiatric manifestations in 3q29Del is consistent with other genomic disorders. For example, the 22q11.2 deletion has a well-known association with schizophrenia but is also associated with intellectual disability (ID), ASD, anxiety, mood disorders, and ADHD [19, 20]. A similar constellation of phenotypes, including ASD, ADHD, ID, SZ, and anxiety, has been identified in 16p11.2 deletion and duplication syndromes [21, 22], 7q11.23 duplication syndrome [23], and 1q21.1 deletion syndrome [24]. Thus, risk for multiple neuropsychiatric phenotypes appears to be a feature common to many genomic disorders, including 3q29 deletion syndrome.

The present study aims to improve the current understanding of 3q29 deletion-associated neuropsychiatric and neurodevelopmental phenotypes, and ASD in particular, by examining data from comprehensive, standardized questionnaires in the largest cohort of individuals with 3q29Del ever assembled. Developing a clearer and more comprehensive picture of 3q29 deletion-associated phenotypes will aid in management of the syndrome for both families and clinicians, which may in turn improve long-term outcomes. Additionally, a careful description of the phenotypic spectrum of 3q29Del provides a basis for cross-disorder comparison between genomic disorders, which may ultimately create inroads for identifying common mechanisms underlying 3q29Del and similar CNV disorders.

\section{Methods and materials \\ Sample}

Individuals with 3q29Del were ascertained through the internet-based 3q29 deletion registry (https://3q29deletion.patientcrossroads.org) as previously reported [5]. Briefly, information about the registry was emailed to health care providers, medical geneticists, genetic counselors, and support organizations; the registry is also advertised via Google AdWords, where specific keywords were chosen to target the registry website in internet searches. Participant recruitment, informed consent and assent, and data collection are all performed through the registry website. Data were securely downloaded and deidentified for analysis. After data cleaning of the electronic records (removing spam accounts, duplicate records, and related individuals), 93 3q29Del registrants (58.1\% male) were included in the present study, ranging in age from $0.1-41.0$ years (mean $=10.0 \pm 8.6$ years). Clinical diagnosis of 3q29 deletion syndrome was confirmed in $58 \%$ of our study subjects via review of clinical genetics reports and/or medical records. To confirm that adaptation of standardized questionnaires to an online format did not skew results, 64 typically developing controls $(51.6 \%$ male) were included, ranging in age from $1.0-41.0$ years (mean $=9.9 \pm 7.2$ years). Controls were recruited via emails sent to intramural CDC and Emory listservs and invited to fill out surveys in an identical fashion to cases. Controls reporting a clinical diagnosis of any neurodevelopmental disorder were excluded ( $n=$ 1). Description of the study sample can be found in 
Table 1. This study was approved by Emory University's Institutional Review Board (IRB00064133).

\section{Questionnaires}

Upon registration, the participant or his/her parent completed a custom medical and demographic questionnaire. This questionnaire includes questions on the sex, birthdate, race, and ethnicity of the participant, as well as a detailed medical history, including developmental milestones and prior clinical diagnoses of any neuropsychiatric or neurodevelopmental disorders [5].

Four standardized questionnaires were used to assess ASD-related symptomology and general behavioral problems in the participants. The Social Responsiveness Scale (SRS; preschool, school-age, and adult forms; $n=$ 48 3q29Del, 56 controls) is a 65-item, 4-point Likertscaled questionnaire designed to assess ASD-related symptoms along a normative continuum [25]. The Social Communication Questionnaire (SCQ, $n=33$ 3q29Del, 46 controls) is a 40-item, yes/no questionnaire designed to assess ASD-related symptoms keyed to diagnostic and statistical manual (DSM) criteria [26]. The Autism Spectrum Screening Questionnaire (ASSQ, $n=24$ 3q29Del, 35 controls) is a 27-item, yes/somewhat/no questionnaire designed to assess ASD-related symptoms in high-functioning individuals with no to mild ID [27]. The Child Behavior Checklist (CBCL) and Adult
Behavior Checklist (ABCL) are 100-, 113-, or 126-item (CBCL preschool, CBCL school-age, and ABCL, respectively; $n=48$ 3q29Del, 57 controls), 3-point Likert-scaled questionnaires designed to assess behavioral or developmental problems $[28,29]$. Data from the CBCL and $\mathrm{ABCL}$ were pooled for analysis. All standardized questionnaires were adapted for the online 3q29 deletion registry and were completed by the participant or parent/guardian of the participant upon registration. Some participants were not eligible to complete the standardized questionnaires because the proband was too young. Demographic characteristics of the respondents for each questionnaire can be found in Additional file 1: Table S1. demonstrating that the average age and sex distribution of participants who completed the medical and demographic questionnaire were not different from the average age and sex distribution of participants who completed each standardized form.

\section{Analysis}

Data from standardized questionnaires were imported into R [30] and were recoded and scored according to the publisher's guidelines. Features of interest from the medical history questionnaire (heart defects, age at walking, ASD diagnosis, global developmental delay/mental retardation (GDD/MR) diagnosis) were recoded for analysis as follows: heart defects, yes/no; age at walking,

Table 1 Characteristics of study participants with 3q29Del and controls

\begin{tabular}{|c|c|c|c|}
\hline & 3 q29 deletion syndrome & Control & $p$ value \\
\hline Age, years (mean $\pm S D$ ) & $10.0 \pm 8.6$ & $9.9 \pm 7.2$ & 0.945 \\
\hline $\operatorname{Sex}(n, \%)$ & & & 0.521 \\
\hline Male & $54(58.1 \%)$ & $33(51.6 \%)$ & \\
\hline Female & 39 (41.9\%) & $31(48.4 \%)$ & \\
\hline Race $(n, \%)$ & & & 0.0003 \\
\hline White & $81(87.1 \%)$ & $41(64.1 \%)$ & \\
\hline Black/African American & $2(2.2 \%)$ & $12(18.8 \%)$ & \\
\hline Other & $10(10.8 \%)$ & $9(14.1 \%)$ & \\
\hline Blank & $0(0 \%)$ & $2(3.1 \%)$ & \\
\hline Heart defect $(n, \%)$ & & & 2.37E- 07 \\
\hline Yes & $27(29.0 \%)$ & $2(3.1 \%)$ & \\
\hline No & $54(58.1 \%)$ & $61(95.3 \%)$ & \\
\hline Blank & $12(12.9 \%)$ & $1(1.6 \%)$ & \\
\hline Age at walking $(n, \%)$ & & & $2.16 \mathrm{E}-09$ \\
\hline Normal & $42(45.7 \%)$ & $60(93.8 \%)$ & \\
\hline Delayed & $23(25.0 \%)$ & $1(1.6 \%)$ & \\
\hline Extremely delayed & $12(13.0 \%)$ & $1(1.6 \%)$ & \\
\hline Unsure & $10(10.9 \%)$ & $2(3.1 \%)$ & \\
\hline Not applicable & $5(5.4 \%)$ & $0(0 \%)$ & \\
\hline
\end{tabular}

Demographic data collected from the custom medical and demographic questionnaire completed by participants upon enrollment in the online $3 q 29$ Registry. $p$ values were calculated with Student's $t$ test (age), Fisher's exact test (race, heart defect, age at walking), or Pearson's chi square test (sex) 
binned as normal ( $\leq 18$ months), delayed (19-24 months), and extremely delayed (>24 months); ASD diagnosis, yes/no; and GDD/MR diagnosis yes (reported diagnosis of global developmental delay and/or mental retardation)/no. To compare responses between 3q29Del cases and controls, linear models and logistic regression models were implemented using the stats $R$ package [30]. To perform case-only analysis within 3q29Del cases, linear models and logistic regression models were implemented using the stats $R$ package [30] and cumulative link proportional-odds models were implemented using the ordinal $\mathrm{R}$ package [31]. All statistical models included age, race, and sex as covariates. To compare rates of self-reported diagnoses and demographic parameters between 3q29Del cases and controls, Fisher's exact test was implemented using the stats $\mathrm{R}$ package [30]. To compare rates of selfreported diagnoses in 3q29Del cases to population prevalence values, one-sample proportion tests with Yates' continuity correction were implemented using the stats $\mathrm{R}$ package [30]. To compare sex distribution between 3q29Del participants and controls, Pearson's chi square test was implemented using the stats $R$ package [30]. To compare age distribution in 3q29Del participants and controls, two sample $t$ test was implemented using the stats $R$ package [30]. To compare scores in 3q29Del participants to mean values for children with idiopathic ASD, one sample $t$ test was implemented using the stats $\mathrm{R}$ package [30]. Odds ratios and $p$ values were calculated using the fmsb $R$ package [32]. Figures were generated using the plotly and ggplot2 $\mathrm{R}$ packages [33, 34].

\section{Sensitivity Analysis}

The questionnaires for 90 participants with 3q29Del (96.8\%) were completed by a parent or guardian ("parent-registered"), while 3 participants with 3q29Del (3.2\%) completed all questionnaires themselves ("selfregistered"). All control participants were parentregistered. To assess whether responses from the selfregistered 3q29Del participants were influencing the results, self-registrants were removed and the data were re-analyzed. Self-registrants were not found to have a significant effect on the analyses (Additional file 1: Tables S2 and S3). All results include both parent- and self-registrants.

\section{Results}

\section{Self-report of neuropsychiatric diagnosis in 3q29Del}

Self-report of neuropsychiatric diagnoses in our 3q29Del study subjects (Table 2) revealed a higher prevalence of neuropsychiatric disorder diagnoses compared to controls, including anxiety (28.0\%), and compared to general population frequencies, including ASD (29.0\%, Fig. 2a) and GDD/MR (59.1\%) (Table 2), confirming prior work by our group [5]. Reported rates of conduct disorder $(1.1 \%$ vs. $3.5 \%)$ and oppositional defiant disorder $(3.2 \%$ vs. $3.5 \%)$ were similar to those observed in the general population. While a small proportion of participants reported diagnoses of bipolar/manic depression (4.3\%), depression (6.5\%), and schizophrenia (4.3\%), we focused on ASD due to the young age (mean $=10.0$ years) of our study population, since many study participants have not reached the age of risk for schizophrenia and other adult-onset disorders. Despite this young age, the selfreported rate of SZ diagnoses in our adult study subjects (age $>18$ years, $n=13$ ) was $15-30$ times higher than expected $(15.4 \%$ compared to an expected $0.5-1 \%$ in the general population; $n=2$ ) [37-41] and the frequency of bipolar disorder was $\sim 1.8$ times higher than expected [42]. A summary of neuropsychiatric diagnoses can be found in Table 2.

\section{SRS, SCQ, ASSQ, and CBCL/ABCL scores}

In 3q29 deletion study subjects, the mean SRS score was in the moderate range ( $\mathrm{T}$-score $=71.8$ ), the mean ASSQ score was in the clinical range $($ mean $=22.2)$, and the mean $\mathrm{CBCL} / \mathrm{ABCL}$ score was in the borderline range (T-score $=62.5)$. The mean SCQ score in 3q29 deletion carriers was at the extremely high end of the normal range (mean $=13.9$, clinical cutoff $=15)$ and elevated as compared to controls (mean $=3.5$ ). Mean scores for typically developing controls were all in the normal range (SRS T-score $=45.9$, ASSQ mean $=2.2, \mathrm{CBCL} / \mathrm{ABCL} \mathrm{T}$ score $=41.8$, SCQ mean $=3.5)$ (Fig. 1). Participants with 3q29Del scored significantly higher than typically developing controls on all four scales $(p<3.0 \mathrm{E}-12$, Additional file 1: Table S4).

\section{Standardized scores stratified by ASD diagnosis}

Next, we examined the relationship between SRS scores and reported ASD diagnosis, to determine whether the score inflation we observed in our study population as a whole was largely due to the increased prevalence of ASD. As expected, we observed that individuals with 3q29Del and an ASD diagnosis scored significantly higher than both controls and individuals with 3q29Del without an ASD diagnosis (3q29Del with ASD $n=17$, Tscore $=82.41 ; 3 \mathrm{q} 29 \mathrm{Del}$ without $\mathrm{ASD} n=31$, T-score $=$ 65.90; control $n=56$, T-score $=45.90 ; p<3.0 \mathrm{E}-13$; Fig. $2 \mathrm{~b})$. We were interested to observe that individuals with 3q29Del without an ASD diagnosis also scored significantly higher than controls (3q29Del without ASD $n=$ 31, T-score $=65.90$; control $n=56, \mathrm{~T}$-score $=45.90 ; p=$ 2.16E-13; Fig. 2b), indicating that increased SRS scores in individuals with 3q29Del are not driven by ASD diagnostic status alone (Additional file 1: Table S5). Similar features were observed in the contribution of ASD 
Table 2 Self-reported neuropsychiatric diagnoses

\begin{tabular}{|c|c|c|c|c|c|c|c|}
\hline & $3 q 29$ deleti & n syndrome & & Control & & & $p$ value; $3 q 29$ Del vs. control \\
\hline & Total & Male & Female & Total & Male & Female & \\
\hline GDD/MR (n, \%) & & & & & & & $<2.20 \mathrm{E}-16$ \\
\hline Yes & $55(59.1 \%)$ & $31(57.4 \%)$ & $24(61.5 \%)$ & $1.14 \% *$ & $1.48 \% *$ & $0.90 \% *$ & \\
\hline No & $38(40.9 \%)$ & $23(42.6 \%)$ & $15(38.5 \%)$ & $64(100 \%)$ & $33(100 \%)$ & $31(100 \%)$ & \\
\hline $\operatorname{ASD}(n, \%)$ & & & & & & & $<2.20 \mathrm{E}-16$ \\
\hline Yes & $27(29.0 \%)$ & $20(37.0 \%)$ & $7(17.9 \%)$ & $1.47 \% *$ & $2.34 \% *$ & $0.52 \% *$ & \\
\hline No & $66(71.0 \%)$ & $34(63.0 \%)$ & $32(82.1 \%)$ & $64(100 \%)$ & $33(100 \%)$ & $31(100 \%)$ & \\
\hline Anxiety $(n, \%)$ & & & & & & & 0.001 \\
\hline Yes & $26(28.0 \%)$ & $15(27.8 \%)$ & $11(28.2 \%)$ & $4(6.2 \%)$ & $2(6.1 \%)$ & $2(6.5 \%)$ & \\
\hline No & $67(72.0 \%)$ & $39(72.2 \%)$ & $28(71.8 \%)$ & $60(93.8 \%)$ & 31 (93.9\%) & $29(93.5 \%)$ & \\
\hline Bipolar/Manic Depression (n. \%) & & & & & & & 0.146 \\
\hline Yes & $4(4.3 \%)$ & $2(3.7 \%)$ & $2(5.1 \%)$ & $0(0 \%)$ & $0(0 \%)$ & $0(0 \%)$ & \\
\hline No & 89 (95.7\%) & $52(96.3 \%)$ & 37 (94.9\%) & $64(100 \%)$ & $33(100 \%)$ & $31(100 \%)$ & \\
\hline Conduct Disorder ( $n, \%)$ & & & & & & & 1.00 \\
\hline Yes & $1(1.1 \%)$ & $1(1.9 \%)$ & $0(0 \%)$ & $0(0 \%)$ & $0(0 \%)$ & $0(0 \%)$ & \\
\hline No & $92(98.9 \%)$ & $53(98.1 \%)$ & $39(100 \%)$ & $64(100 \%)$ & $33(100 \%)$ & $31(100 \%)$ & \\
\hline Depression ( $n, \%)$ & & & & & & & 1.00 \\
\hline Yes & $6(6.5 \%)$ & $2(3.7 \%)$ & $4(10.3 \%)$ & $4(6.2 \%)$ & $4(12.1 \%)$ & $0(0 \%)$ & \\
\hline No & $87(93.5 \%)$ & $52(96.3 \%)$ & 35 (89.7\%) & $60(93.8 \%)$ & 29 (87.9\%) & 31 (100\%) & \\
\hline Oppositional Defiant Disorder ( $n, \%)$ & & & & & & & 0.271 \\
\hline Yes & $3(3.2 \%)$ & $2(3.7 \%)$ & $1(2.6 \%)$ & $0(0 \%)$ & $0(0 \%)$ & $0(0 \%)$ & \\
\hline No & $90(96.8 \%)$ & $52(96.3 \%)$ & $38(97.4 \%)$ & $64(100 \%)$ & $33(100 \%)$ & $31(100 \%)$ & \\
\hline Panic Attacks ( $n, \%)$ & & & & & & & 0.045 \\
\hline Yes & $12(12.9 \%)$ & $9(16.7 \%)$ & $4(10.3 \%)$ & $2(3.2 \%)$ & $0(0 \%)$ & $2(6.5 \%)$ & \\
\hline No & $81(87.1 \%)$ & 45 (83.3\%) & 35 (89.7\%) & $62(96.8 \%)$ & $33(100 \%)$ & 29 (93.5\%) & \\
\hline Schizophrenia $(n, \%)$ & & & & & & & 0.146 \\
\hline Yes & $4(4.3 \%)$ & $1(1.9 \%)$ & $3(7.7 \%)$ & $0(0 \%)$ & $0(0 \%)$ & $0(0 \%)$ & \\
\hline No & 89 (95.7\%) & $53(98.1 \%)$ & $36(92.3 \%)$ & 64 (100\%) & $33(100 \%)$ & 31 (100\%) & \\
\hline
\end{tabular}

Characteristics of self-reported neuropsychiatric diagnoses in study participants with 3q29Del and controls. Asterisks indicate where 3q29Del was compared to general population prevalence values $[35,36] . p$ values were calculated with one-sample proportion test with Yates' continuity correction when comparing to population prevalence and Fisher's exact test when comparing to controls

diagnosis status to SCQ scores (Additional file 1: Figure S1 and Table S6).

\section{Standardized scores stratified by sex}

Both males and females with 3q29Del reported a significantly increased frequency of ASD diagnoses, with a substantially greater burden for ASD on females with 3q29Del. Males with 3q29Del are at 16-fold increased risk for ASD as compared to the general population (37.0\% vs. $2.34 \%, \mathrm{OR}=24.6, p=6.06 \mathrm{E}-09)$ and females are at 34-fold risk compared to the general population (17.9\% vs. $0.52 \%, \mathrm{OR}=41.8, p=4.78 \mathrm{E}-05)$ (Fig. 2a) [35], resulting in a male:female ratio in our study population of 2:1, as compared to the general population ratio of 4 : 1. Taken together, this indicates that the 3q29 deletion elevates the risk for ASD in females more substantially than in males.

Based on the sex differences in ASD risk for individuals with 3q29Del, we also examined possible sex differences in scores. We found that both males and females with 3q29Del scored significantly higher than controls (3q29Del male $n=26$, T-score $=74.31$; control male $n=$ 30, T-score $=45.80 ; p=7.70 \mathrm{E}-11 ; 3 \mathrm{q} 29 \mathrm{Del}$ female $n=$ 22, T-score $=68.73$; control female $n=26, \mathrm{~T}$-score $=$ 46.04; $p=7.42 \mathrm{E}-09$ ); while 3q29Del males have higher scores than females, the differences are not statistically significant (3q29Del male $n=26, \quad$ T-score $=74.31$; 3q29Del female $n=22$, T-score $=68.73 ; p>0.05$; Fig. 2c). After stratifying our study population further by sex and ASD diagnosis status, we determined that both male and female 3q29Del participants without an ASD diagnosis 


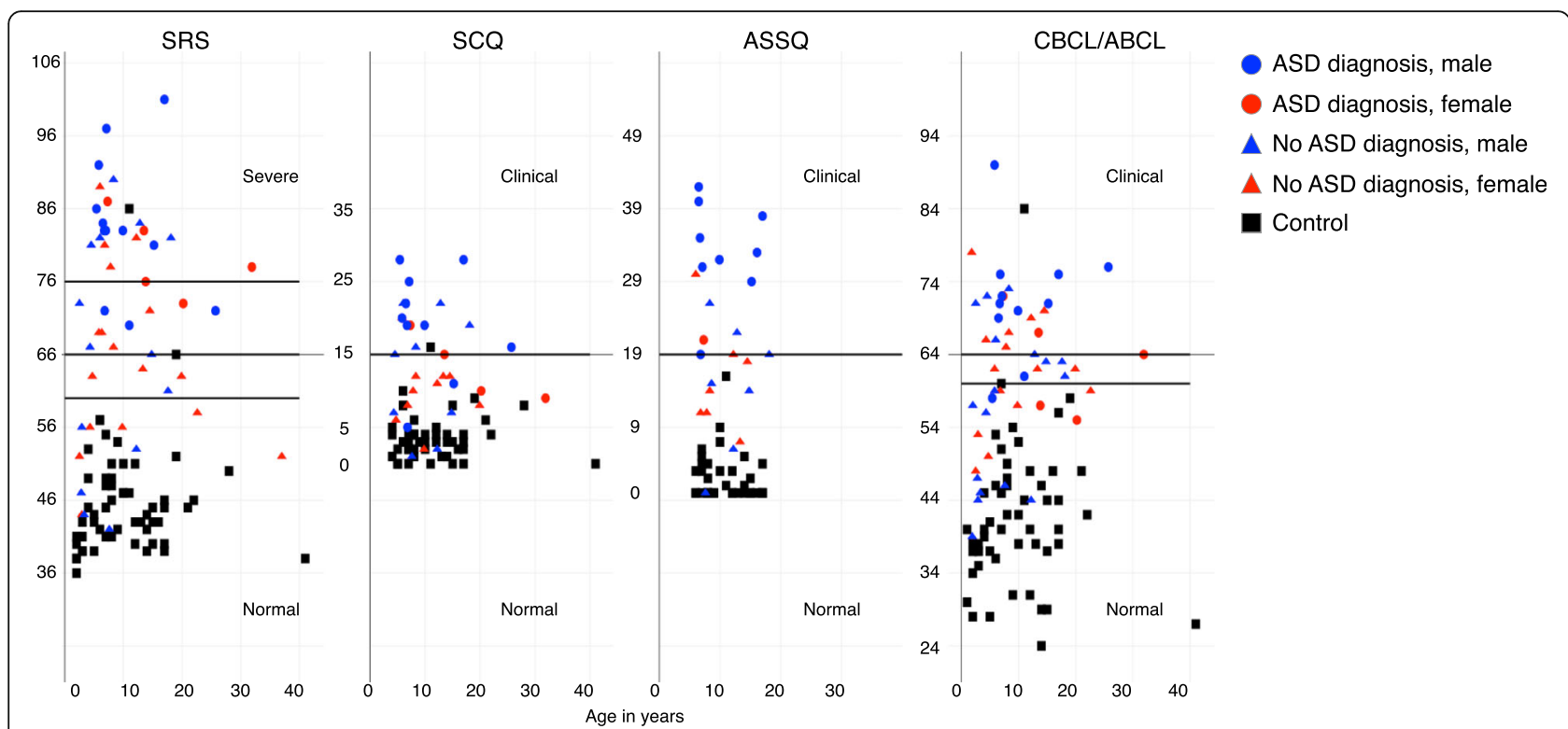

Fig. 1 Score distribution for 3q29Del and controls on the SRS, SCQ, ASSQ, and CBCL/ABCL. Total scores on the SRS ( $n=483 q 29 \mathrm{Del}, 56 \mathrm{control})$, SCQ ( $n=$ 33 3q29Del, 46 control), ASSQ ( $n=24$ 3q29Del, 35 control), and CBCL/ABCL ( $n=48$ 3q29Del, 57 control) for registry participants. Self-reported diagnosis of ASD is denoted by shape (circle/ASD, triangle/no ASD), and sex of participant is denoted by color (red/female, blue/male). Controls are shown in black

had significantly higher scores than controls (3q29Del male without ASD $n=14$, T-score $=66.29$; control male $n=30$, T-score $=45.80 ; p=1.20 \mathrm{E}-06 ; 3 q 29 \mathrm{Del}$ female without ASD $n=17$, T-score $=65.69$; control female $n=$ 26 , T-score $=46.04 ; p=5.04 \mathrm{E}-07$; Fig. $2 \mathrm{~d}$ ). Taken together, this suggests that increased SRS scores in individuals with 3q29Del are not driven by sex alone or by sex and ASD diagnosis status in combination (Additional file 1: Table S5); rather, the presence of the deletion itself confers a greater risk for social disability. Furthermore, these data show an enrichment for female ASD in our study population, based on the reduction in male bias and the highly similar scores between males and females with 3q29Del, irrespective of ASD diagnosis status. Similar features were observed in the contribution of sex to SCQ scores (Additional file 1: Figure S1 and Table S6).

\section{ASD presentation of 3q29Del}

While total scores on the SRS, SCQ, ASSQ, and CBCL/ $\mathrm{ABCL}$ can give an indication of the overall level of impairment of individuals, sub-scores can reveal nuanced deficits in specific behavioral domains. To this end, we analyzed all SRS sub-scales (Social Awareness, Social Cognition, Social Communication, Social Motivation, Restricted Interests and Repetitive Behaviors, and Social Communication and Interaction) to better understand the extent of social disability in our study population; our goal was to determine whether our observed total score inflation was due to a specific severe deficit in a few domains or if individuals with 3q29Del showed high scores across all sub-scales. The mean score for the Restricted Interests and Repetitive
Behaviors sub-scale was in the severe range $($ T-score $=$ 77.3). Mean scores for Social Awareness $(\mathrm{T}$-score $=67.3$ ), Social Cognition $(\mathrm{T}$-score $=69.1)$, Social Communication $(\mathrm{T}$-score $=69.7)$, and Social Communication and Interaction (T-score $=69.5$ ) were all in the moderate range. Notably, the mean score for Social Motivation was in the mild range $(\mathrm{T}$-score $=62.1$, Fig. 3a, Table 3). This sub-score profile is strikingly different from that reported in studies of idiopathic ASD, where children tend to score equally high on all sub-scales (3q29Del Social Motivation T-score $=62.1$, idiopathic ASD Social Motivation T-score $=78.4, p=7.66 \mathrm{E}$ -11) [43]. This atypical behavioral profile is supported by clinical data; direct assessment of individuals with 3q29Del by clinicians affiliated with the Emory 3q29 Project (http:// genome.emory.edu/3q29/, [44]) shows less impaired social motivation as compared to children with idiopathic ASD.

\section{ASD presentation stratified by sex}

To determine whether this unusual SRS sub-score profile was influenced by sex, we examined profiles of male and female 3q29 deletion carriers separately. We found that the shape of the profiles was identical, with males scoring on average 5 points higher than females on every sub-scale $(n=26$ male, 22 female; $p>0.05$; Fig. 3b; Table $3)$, demonstrating that the social disability in 3q29Del is not qualitatively different between males and females.

\section{ASD presentation stratified by ASD diagnosis}

We then stratified our study subjects according to reported ASD diagnosis status and examined subscale scores separately for 3q29Del individuals reporting a 


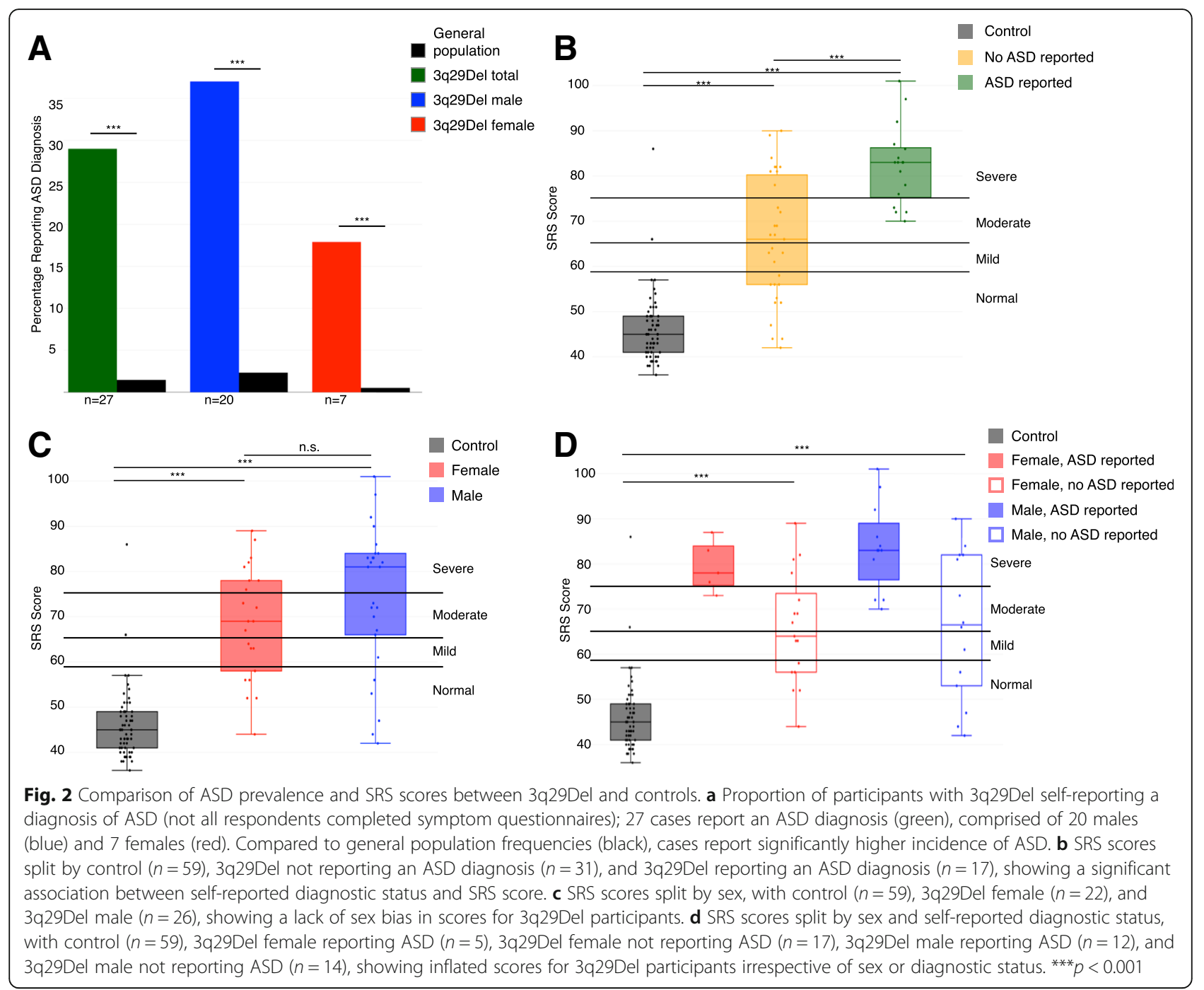

diagnosis of ASD and those not reporting a diagnosis of ASD. We observed that the shape of the profile is shared between 3q29Del individuals reporting a diagnosis of ASD and those not reporting a diagnosis of ASD, with individuals reporting a diagnosis of ASD scoring on average 10-15 points higher on every sub-scale (Fig. 3c). As expected, 3q29Del participants with ASD scored significantly higher on all sub-scales than 3q29Del participants without ASD ( $n=17$ with ASD, 31 without ASD; $p<0.005$; Table 3); however, 3q29Del participants without ASD still scored significantly higher than controls on all sub-scales $(n=31$ without ASD, 56 control; $p<$ 5.0E- 05; Table 3).

\section{Additional neuropsychiatric phenotypes in 3q29Del}

To further assess behavioral features associated with the 3q29 deletion, we examined the DSM-oriented Attention Deficit/Hyperactivity Problems, Anxiety Problems, and Depressive Problems sub-scales from the CBCL and
ABCL. These DSM-oriented sub-scales align with neuropsychiatric diagnoses reported by individuals with 3q29Del [5]. Individuals with 3q29Del scored significantly higher than typically developing controls on all three scales (3q29Del Attention Deficit/Hyperactivity Problems T-score $=61.0$, control Attention Deficit $/$ Hyperactivity Problems T-score $=51.3$, 3q29Del Anxiety Problems $\mathrm{T}$-score $=60.9$, control Anxiety Problems Tscore $=52.9,3 q 29 D e l$ Depressive Problems T-score $=$ 62.7, control Depressive Problems T-score $=52.3$, all $p<$ 0.001, Fig. 3d, Additional file 1: Table S7), supporting previous reports of increased risk for neuropsychiatric phenotypes associated with the 3q29 deletion [5].

\section{Confounding due to heart defects and/or ID-related phenotypes}

A previous study of 3q29Del by our group showed that approximately $25 \%$ of individuals with 3q29Del reported a congenital heart defect [5]. Early hypoxic insult due to 


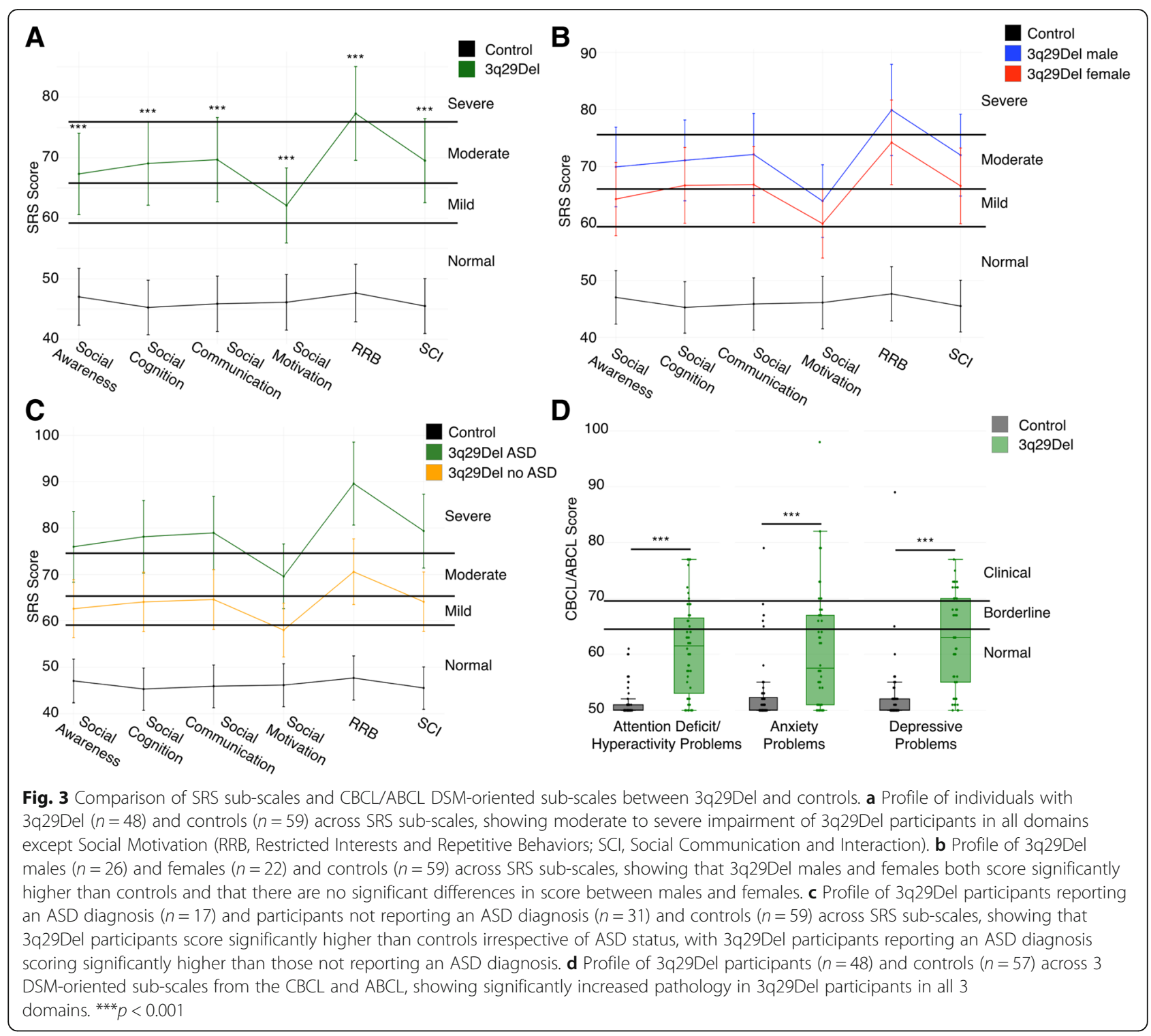

a heart defect has been hypothesized to contribute to later neuropsychiatric and neurodevelopmental outcomes [45-50]. To determine if the high frequency of heart defects in our study population was driving adverse neurodevelopmental outcomes within 3q29Del cases, we implemented generalized linear and cumulative link models to assess the relationship between congenital heart defects and clinical ASD diagnosis, GDD/ MR diagnosis, and age at walking, which has been reported to be a suitable proxy for ID in the absence of available IQ and adaptive behavior measures [51]. Congenital heart defects were not associated with selfreported ASD or GDD/MR diagnoses or age at walking ( $p>0.05$, Additional file 1: Table S8). Individuals with 3q29Del are also commonly diagnosed with mild to moderate ID [5]. To ask whether ASD phenotypes or ASD features were disproportionately overrepresented in individuals with more pronounced ID-related phenotypes and/or heart defects, we stratified the data according to these phenotypes. Within our 3q29Del study population, congenital heart defects were associated with significantly increased scores on the SCQ and CBCL/ $\mathrm{ABCL}(p<0.05)$; however, reported GDD/MR diagnosis and age at walking were not significantly associated with scores on the SRS, SCQ, ASSQ, or CBCL/ABCL ( $p>$ 0.05 , Additional file 1: Table S9). These data indicate that ID-related phenotypes were not driving the increased scores in our study population.

\section{Discussion}

Previous studies have found enrichment of the 3q29 deletion in large samples ascertained based on clinical ASD diagnosis $[17,18]$. We have approached the association of 3q29Del with ASD from a different angle; by 
Table 3 SRS sub-scale score comparison stratified by genotype, ASD status, and sex

\begin{tabular}{|c|c|c|c|c|c|c|c|c|c|c|c|c|}
\hline & \multicolumn{2}{|c|}{ Social awareness } & \multicolumn{2}{|c|}{ Social cognition } & \multicolumn{2}{|c|}{$\begin{array}{l}\text { Social } \\
\text { communication }\end{array}$} & \multicolumn{2}{|c|}{ Social motivation } & \multicolumn{2}{|l|}{ RRB } & \multicolumn{2}{|l|}{$\mathrm{SCl}$} \\
\hline & $\begin{array}{l}\text { Mean } \pm \\
\text { SD }\end{array}$ & $\begin{array}{l}p \\
\text { value }\end{array}$ & $\begin{array}{l}\text { Mean } \pm \\
\text { SD }\end{array}$ & $p$ value & $\begin{array}{l}\text { Mean } \pm \\
\text { SD }\end{array}$ & $p$ value & $\begin{array}{l}\text { Mean } \pm \\
\text { SD }\end{array}$ & $\begin{array}{l}p \\
\text { value }\end{array}$ & $\begin{array}{l}\text { Mean } \pm \\
\text { SD }\end{array}$ & $p$ value & $\begin{array}{l}\text { Mean } \pm \\
\text { SD }\end{array}$ & $p$ value \\
\hline \multicolumn{13}{|l|}{ Genotype } \\
\hline Control & $\begin{array}{l}47.04 \pm \\
8.88\end{array}$ & - & $\begin{array}{l}45.27 \pm \\
7.64\end{array}$ & - & $\begin{array}{l}45.88 \pm \\
8.14\end{array}$ & - & $\begin{array}{l}46.13 \pm \\
7.66\end{array}$ & - & $\begin{array}{l}47.66 \pm \\
8.51\end{array}$ & - & $\begin{array}{l}45.50 \pm \\
7.74\end{array}$ & - \\
\hline 3q29Del & $\begin{array}{l}67.33 \pm \\
13.28\end{array}$ & $\begin{array}{l}1.45 \mathrm{E}- \\
13\end{array}$ & $\begin{array}{l}69.06 \pm \\
15.51\end{array}$ & $\begin{array}{l}1.20 \mathrm{E}- \\
15\end{array}$ & $\begin{array}{l}69.69 \pm \\
13.92\end{array}$ & $\begin{array}{l}<2.00 \mathrm{E} \\
-16\end{array}$ & $\begin{array}{l}62.10 \pm \\
13.52\end{array}$ & $\begin{array}{l}1.62 \mathrm{E}- \\
10\end{array}$ & $\begin{array}{l}77.31 \pm \\
14.25\end{array}$ & $\begin{array}{l}<2.00 E \\
-16\end{array}$ & $\begin{array}{l}69.52 \pm \\
14.63\end{array}$ & $\begin{array}{l}<2.00 \mathrm{E} \\
-16\end{array}$ \\
\hline \multicolumn{13}{|l|}{ Sex } \\
\hline Male control & $\begin{array}{l}45.97 \pm \\
9.15\end{array}$ & - & $\begin{array}{l}45.23 \pm \\
7.42\end{array}$ & - & $\begin{array}{l}45.73 \pm \\
6.34\end{array}$ & - & $\begin{array}{l}46.57 \pm \\
6.58\end{array}$ & - & $\begin{array}{l}47.63 \pm \\
5.59\end{array}$ & - & $\begin{array}{l}45.37 \pm \\
6.60\end{array}$ & - \\
\hline Male 3q29Del & $\begin{array}{l}69.92 \pm \\
13.92\end{array}$ & $\begin{array}{l}7.61 \mathrm{E}- \\
09\end{array}$ & $\begin{array}{l}71.08 \pm \\
17.65\end{array}$ & $\begin{array}{l}1.07 \mathrm{E}- \\
08\end{array}$ & $\begin{array}{l}72.12 \pm \\
15.47\end{array}$ & $\begin{array}{l}1.74 \mathrm{E}- \\
10\end{array}$ & $\begin{array}{l}63.92 \pm \\
15.23\end{array}$ & $\begin{array}{l}3.39 \mathrm{E}- \\
06\end{array}$ & $\begin{array}{l}79.92 \pm \\
14.82\end{array}$ & $\begin{array}{l}2.84 \mathrm{E}- \\
13\end{array}$ & $\begin{array}{l}72.00 \pm \\
16.34\end{array}$ & $\begin{array}{l}7.12 \mathrm{E}- \\
10\end{array}$ \\
\hline Female control & $\begin{array}{l}48.27 \pm \\
8.56\end{array}$ & - & $\begin{array}{l}45.31 \pm \\
8.03\end{array}$ & - & $\begin{array}{l}46.04 \pm \\
9.95\end{array}$ & - & $\begin{array}{l}45.62 \pm \\
8.85\end{array}$ & - & $\begin{array}{l}47.69 \pm \\
11.08\end{array}$ & - & $\begin{array}{l}45.65 \pm \\
9.01\end{array}$ & - \\
\hline Female 3q29Del & $\begin{array}{l}64.27 \pm \\
12.08\end{array}$ & $\begin{array}{l}4.52 \mathrm{E}- \\
06\end{array}$ & $\begin{array}{l}66.68 \pm \\
12.51\end{array}$ & $\begin{array}{l}1.29 \mathrm{E}- \\
08\end{array}$ & $\begin{array}{l}66.82 \pm \\
11.52\end{array}$ & $\begin{array}{l}2.99 \mathrm{E}- \\
08\end{array}$ & $\begin{array}{l}59.95 \pm \\
11.14\end{array}$ & $\begin{array}{l}1.36 \mathrm{E}- \\
05\end{array}$ & $\begin{array}{l}74.23 \pm \\
13.22\end{array}$ & $\begin{array}{l}1.30 \mathrm{E}- \\
09\end{array}$ & $\begin{array}{l}66.59 \pm \\
12.02\end{array}$ & $\begin{array}{l}1.87 \mathrm{E}- \\
08\end{array}$ \\
\hline \multicolumn{13}{|l|}{ ASD Status } \\
\hline Control & $\begin{array}{l}47.04 \pm \\
8.88\end{array}$ & - & $\begin{array}{l}45.27 \pm \\
7.64\end{array}$ & - & $\begin{array}{l}45.88 \pm \\
8.14\end{array}$ & - & $\begin{array}{l}46.13 \pm \\
7.66\end{array}$ & - & $\begin{array}{l}47.66 \pm \\
8.51\end{array}$ & - & $\begin{array}{l}45.50 \pm \\
7.74\end{array}$ & - \\
\hline $\begin{array}{l}\text { No ASD diagnosis } \\
\text { 3q29Del }\end{array}$ & $\begin{array}{l}62.61 \pm \\
13.20\end{array}$ & $\begin{array}{l}5.17 \mathrm{E}- \\
09\end{array}$ & $\begin{array}{l}64.10 \pm \\
15.80\end{array}$ & $\begin{array}{l}5.77 \mathrm{E}- \\
11\end{array}$ & $\begin{array}{l}64.61 \pm \\
13.54\end{array}$ & $\begin{array}{l}1.20 \mathrm{E}- \\
12\end{array}$ & $\begin{array}{l}58.00 \pm \\
13.15\end{array}$ & $\begin{array}{l}1.42 \mathrm{E}- \\
06\end{array}$ & $\begin{array}{l}70.58 \pm \\
11.50\end{array}$ & $\begin{array}{l}<2.00 E \\
-16\end{array}$ & $\begin{array}{l}64.13 \pm \\
14.39\end{array}$ & $\begin{array}{l}5.19 \mathrm{E}- \\
12\end{array}$ \\
\hline $\begin{array}{l}\text { ASD diagnosis } \\
\text { 3q29Del }\end{array}$ & $\begin{array}{l}75.94 \pm \\
8.33\end{array}$ & $\begin{array}{l}2.43 \mathrm{E}- \\
15\end{array}$ & $\begin{array}{l}78.12 \pm \\
10.18\end{array}$ & $\begin{array}{l}<2.00 \mathrm{E} \\
-16\end{array}$ & $\begin{array}{l}78.94 \pm \\
9.18\end{array}$ & $\begin{array}{l}<2.00 \mathrm{E} \\
-16\end{array}$ & $\begin{array}{l}69.59 \pm \\
10.99\end{array}$ & $\begin{array}{l}5.12 \mathrm{E}- \\
12\end{array}$ & $\begin{array}{l}89.59 \pm \\
10.04\end{array}$ & $\begin{array}{l}<2.00 \mathrm{E} \\
-16\end{array}$ & $\begin{array}{l}79.35 \pm \\
9.02\end{array}$ & $\begin{array}{l}<2.00 \mathrm{E} \\
-16\end{array}$ \\
\hline
\end{tabular}

Comparison of mean scores on the SRS sub-scales between study participants with 3q29Del and controls. 3q29Del participants were stratified by ASD status and sex for further analysis. $p$ values were calculated using simple linear regression, adjusting for age, race, and sex

ascertaining subjects with 3q29Del and investigating the prevalence of reported ASD diagnosis and ASD-related phenotypes, the current study complements the existing literature, providing additional evidence for the 3q29 deletion as a genetic risk factor for ASD. Notably, the male:female ratio of self-reported ASD diagnosis in our study population is $2: 1$. This is a reduction from the $4: 1$ male bias observed in idiopathic ASD in the general population. A substantial reduction in male bias in ASD prevalence has been observed in studies of other CNVs and single-gene mutations; a recent study has shown that as the severity of a mutation increases, the sex ratio in ASD prevalence approaches 1:1 [52]. Taken together, this suggests that the $3 \mathrm{q} 29$ deletion is approaching the severe end of the spectrum of ASD-associated mutations.

We have shown that compared to typically developing children, our 3q29Del sample is significantly enriched for ASD features and other behavioral problems, irrespective of a clinical ASD diagnosis. This finding is particularly concerning; while individuals with 3q29Del who have an ASD diagnosis tend to score higher on symptomology scales overall, 3q29Del individuals without an ASD diagnosis still score significantly higher than typically developing children. This indicates several possible explanations: (a) an enrichment for ASD features or social disability that falls short of diagnostic criteria, (b) possible undiagnosed ASD in our study population, or (c) non-specificity of the SRS, and potentially SCQ, for phenotypes other than ASD, such as anxiety. The possibility of undiagnosed ASD in our study population is aligned with anecdotal reports from parents of our study participants, where they have reported concerns about atypical social development that do not appear to have been addressed using gold-standard ASD evaluations. Based on the elevated symptomology scores in our study population, the substantially increased risk for ASD associated with the 3q29 deletion, and the apparent severity of the 3q29 deletion, our data suggest that goldstandard ASD evaluations should be the recommended standard of care for individuals diagnosed with 3q29Del. If implemented, this practice would enable patients to gain access to early interventions, treatments, and therapeutic programs that are known to improve later outcomes.

Based on the SRS sub-scales, participants with 3q29Del display a strikingly different behavioral profile as compared to a study of children with idiopathic ASD [43]. Male and female 3q29Del individuals show substantially less impaired social motivation in the context 
of an otherwise typical ASD profile, with the most severe deficits in the Restricted Interests and Repetitive Behaviors domain. This profile is also observed when dividing scores for 3q29Del participants based on reported ASD diagnosis. This qualitative difference from idiopathic ASD may serve as an inroad to therapeutic interventions in 3q29Del, as well as an investigative inroad to a distinct subtype of ASD. Because social motivation appears to be relatively well-preserved in 3q29Del, this suggests that therapies such as cognitive-behavioral therapy to teach social skills and effective strategies for social interaction may be particularly successful in this patient population.

Some facets of the difference in ASD features between 3q29Del and idiopathic ASD are recapitulated by the scores on the Withdrawn sub-scale of the CBCL and ABCL. Previous studies utilizing the CBCL in idiopathic ASD have found that mean scores for participants with ASD are in the borderline range, with over $50 \%$ of subjects scoring in the borderline or clinical range [53, 54]. While 3q29Del participants generally, as well as males and females separately, score significantly higher than controls, their mean score is still in the normal range (Additional file 1: Figure S2A and B). However, 60\% of 3q29Del participants reporting an ASD diagnosis score in the borderline or clinical range (Additional file 1: Figure S2C and Table S10), which is in line with what is expected based on studies of idiopathic ASD [53, 54]. This is in conflict with the relatively well-preserved social motivation in 3q29Del individuals with ASD identified in our analysis of the SRS sub-scales and suggests that a more refined analysis is merited to identify the true degree of social disability in this population.

We tested the hypothesis that the score inflation observed in our 3q29Del study subjects may be due to the high prevalence of developmental delay or congenital heart defects [5]. Our available data do not support this hypothesis and instead reveal that social disability is equally distributed in our study population. Lack of direct measures of intellectual disability, and errors or missing data in self-report measures, may obscure this relationship; however, numerous studies of the relationship between ID and ASD in genomic disorders suggests that when the population is stratified by the presence of a specific genetic variant, the association between these two phenotypes diminishes. A large study of several genetic disorders showed that the prediction of genetic diagnosis based on ADI-R scores was not confounded by IQ [55], a study of 7q11.23 duplication found that IQ was not significantly associated with ASD status [56], and multiple studies of 22q11.2 deletion have shown that IQ is not significantly associated with SRS score, ASD severity, and ASD status [57-59]. A question ripe for future investigation is the potential role for microcephaly in the ASD-related phenotypes observed in 3q29Del. Microcephaly, ASD, and ID are associated with the 16p11.2 duplication [21]; microcephaly has been shown to be associated with ASD and ID in probands with pathogenic CNVs [60]; and children with "complex autism", defined as ASD with microcephaly and/or dysmorphology, have significantly lower cognitive function than children with "essential autism" [61]. Reports have shown a high prevalence of microcephaly in 3q29Del [3, $4,12]$; however, this question was not probed in the current study due to the high rate $(>50 \%)$ of 3q29Del participants responding "Unsure" to the medical history questionnaire regarding their child's head circumference at birth, rendering this data unreliable. Ongoing studies with direct evaluation of study subjects [44] will address these questions.

While this study is the most comprehensive study of behavioral phenotypes in 3q29Del to date, it is not without limitations. All of the data used in the present study were collected from questionnaires completed by the parents and guardians of individuals with 3q29Del, which introduces several potential sources of bias. Some studies have questioned the validity and reliability of parent-report data [62]; however, a recent study in Williams syndrome patients has shown that parents are more accurate in predicting their child's social behaviors than the child themselves [63]. The responses to the medical and demographic questionnaire are more likely to include error due to the fact that the data is retrospective. By limiting our study to only a few key points in the medical history (heart defects, age at walking, and ID/ASD diagnosis), we aimed to reduce recall errors; however, we only had proxies for ID, rather than direct evaluation of cognitive ability. Further, the sample sizes for our stratified analyses were small, rendering them underpowered; while the differences between males and females were not statistically significant, males do score higher than females on all measures. Studies with larger sample size will be better able to assess the importance of and estimate the true effect size of any difference between males and females. Additionally, there is likely ascertainment bias within our sample. First, our sample of 93 individuals with 3q29Del is $87.1 \%$ white, indicating that we are not adequately reaching minority populations. Second, parents that register their children and complete in-depth questionnaires are likely to be highly motivated, possibly because their children experience significant morbidity - a potential indication that we are sampling from the extreme of the phenotypic distribution of 3q29Del. Thus, scores on the standardized questionnaires, as well as rates of heart defects and clinical neuropsychiatric diagnoses, may be higher in our study sample than in the general 3q29Del population. Additionally, the odds ratios calculated for the increased risk 
for ASD associated with the 3q29 deletion may also be overestimated, due to the combined effects of self-report data and ascertainment bias; however, if this increased risk is replicated using gold-standard diagnostic measures, it could provide valuable insight into possible sexspecific effects of the deletion. Finally, the lack of observed association between congenital heart defects and neurodevelopmental outcomes may be obscured by the high rate of patent ductus arteriosus in 3q29 deletion syndrome [5], which is a relatively mild heart defect; however, the low number of participants with different types of heart defects rendered analyses to assess their associations with neurodevelopment underpowered (Additional file 1: Table S11). Ongoing studies by the Emory 3q29 Project (http://genome.emory.edu/3q29/), including direct in-person patient evaluations [44] aim to address some of the weaknesses of the present work by performing comprehensive gold-standard evaluations by expert clinicians.

While direct in-person evaluations are the ideal method to corroborate the findings of this study, the low population frequency of the 3q29 deletion and geographic dispersal of our study population (Additional file 1: Figure S3) renders this approach infeasible for a large number of study subjects. However, a small number of 3q29 deletion study subjects have been directly assessed as part of the Emory 3q29 Project (http://genome.emory.edu/3q29/). We confirm high concordance between registry-leveraged data and goldstandard direct evaluation, as all participants qualifying for an ASD diagnosis based on gold-standard evaluation have clinically significant scores on the SRS and all participants reporting an ASD diagnosis qualified for an ASD diagnosis after gold-standard assessment by the Emory 3q29 Project team (Additional file 1: Table S12). Notably, one participant that did not report a prior diagnosis of ASD received an ASD diagnosis after assessment by our team, supporting our hypothesis that ASD may be underdiagnosed in the 3q29Del population. Five additional participants with a clinically significant SRS score did not qualify for an ASD diagnosis, suggesting that the SRS is not selectively identifying children with ASD in participants with 3q29Del, possibly due to the high rates of reported anxiety in our study population. However, this comparison does suggest that our analysis, though based on self-report data, reveals valid conclusions about behavioral phenotypes in 3q29 deletion syndrome. For genetic syndromes with low population frequencies, data collection through remote means such as online patient registries remains a valuable phenotyping tool.

While the current understanding of the 3q29 deletion is still evolving, there are more well-understood $\mathrm{CNV}$ disorders that can be used as a comparison point to determine whether the social disability phenotypes described in this study are distinct to 3q29Del. These include Williams Syndrome (WS, or the 7q11.23 deletion), the reciprocal 7q11.23 duplication, 16p11.2 deletion and duplication, Smith-Magenis Syndrome (SMS), and 22 q11.2 deletion. WS is typically associated with hypersociability [64], and patients with WS show more problems with social cognition than with pro-social behaviors [65], similar to what we have observed in our population of individuals with 3q29Del. However, the prevalence of restricted interests and repetitive behaviors appears to be lower in WS as compared to 3q29Del [65], and the mean SRS sub-scale Social Motivation score indicates enhanced social motivation in WS as compared to 3q29Del (WS mean T-score $=55.24$, 3q29Del mean $\mathrm{T}$ score $=62.1, p=0.0005$ ) [66]. Studies of the reciprocal 7q11.23 duplication showed that parent-reported ASD symptomology via standardized questionnaires was higher than ASD features as assessed by gold-standard instruments, that some probands had been diagnosed with ASD based on delayed speech and social anxiety but did not qualify for ASD via gold-standard measures, that substantially more males than females qualified for an ASD diagnosis, and that $7 \mathrm{q} 11.23$ duplication probands were indistinguishable from children with idiopathic ASD on measures of ASD severity and diagnosis status [56, 67, 68]. This is qualitatively different from our 3q29Del population; all of the participants with a prior ASD diagnosis who were later assessed by the Emory 3q29 Project team had their diagnosis confirmed using gold-standard measures (Additional file 1: Table S12), the male:female ratio in our sample is $2: 1$, and we see significant differences between 3q29Del cases and idiopathic ASD [43] on the SRS Social Motivation sub-scale.

Similar to 7q11.23 duplication, ASD probands with 16 p11.2 deletion or duplication were indistinguishable from idiopathic ASD probands [68]; probands with 16p11.2 deletion also have a significantly higher mean SRS score as compared to 3q29Del (16p11.2 mean Tscore $=77.8,3 q 29 \mathrm{Del}$ mean $\mathrm{T}$-score $=71.8, p=0.003$ ) [22], and males with 16p11.2 deletion are at increased risk for ASD compared to females and are overrepresented when cases are ascertained based on neurodevelopmental disorders $[69,70]$, indicating a different sexbased ASD risk as compared to 3q29Del. A study of 16 p11.2 duplication probands found that scores on the SRS Social Motivation sub-scale were not significantly different from controls and that ASD cases had specific impairments in social cognition and communication [71]; 3q29Del cases score significantly higher than controls on the SRS Social Motivation sub-scale and do not have substantially higher scores on the Social Cognition or Social Communication sub-scales relative to the other SRS sub-scales. 
A recent study of SMS showed that female probands scored higher than males on SRS sub-scales and the sex ratio of ASD was reversed, with more females than males qualifying for a diagnosis [72], which we do not observe in our 3q29Del study population. Finally, studies of 22q11.2 deletion show some similarities with 3q29Del, including SRS total scores that are not significantly different, high levels of ASD features in the absence of ASD diagnosis, and a male:female ASD ratio of approximately 1:1 [19, 58, 59, 73]; however, 22q11.2 deletion probands have a significantly lower mean ASSQ score as compared to 3q29Del (22q11.2 mean $=11$, 3q29Del mean $=22.2, p=0.00004)$, and 3q29Del cases have significantly higher scores on several CBCL/ABCL sub-scales (Additional file 1: Table S13) [74, 75]. Taken together, this evidence suggests that while the ASD features in 3q29Del reported in this study share some characteristics with other $\mathrm{CNV}$ disorders, the complete constellation of symptoms is discrete from previously described genomic syndromes.

There are significant strengths of this study as compared to previous studies of 3q29Del. First, this is the largest cohort of individuals with 3q29Del ever assembled. This is a critical step in capturing the true phenotypic spectrum associated with the 3q29 deletion. Our use of standardized questionnaires allowed for comparison between ASD features present in 3q29Del and those reported in idiopathic ASD and ASD in other CNV disorders. Additionally, our online patient registry allows for remote data collection, which has enabled us to expand our sample size. This study has shown that highquality, comprehensive medical history and symptomology data can be collected through an online patient registry, effectively reducing the patient-ascertainment burden associated with studying rare disorders. Taken together, these attributes make the present study an excellent complement to previously published case reports on individuals with 3q29Del; by capturing a larger patient base with systematic assessments, we are able to more accurately measure the presence of a variety of neuropsychiatric and neurodevelopmental phenotypes associated with the 3q29 deletion. The findings reported here indicate that comprehensive neuropsychiatric and neurodevelopmental assessments with gold standard tools are merited for individuals diagnosed with 3q29Del, and that such assessments should be the standard of care for this patient population.

\section{Conclusions}

The present study confirms previous reports of phenotypes in 3q29Del, as well as expanding the spectrum of behavioral phenotypes associated with the deletion. We found that individuals with 3q29Del report a significantly higher prevalence of ASD diagnosis than the general population, and significantly elevated scores on the SRS, SCQ, ASSQ, and CBCL/ABCL irrespective of ASD diagnosis indicate significant social disability overall in our study population. Further, 3q29Del participants showed a distinct profile of ASD-related phenotypes on the SRS sub-scales, marked by less impaired scores on the Social Motivation sub-scale and extremely high scores on the Restricted Interests and Repetitive Behaviors sub-scale. This score profile is consistent between 3q29Del males and females and between 3q29Del participants with and without ASD, suggesting that it may be a hallmark behavioral feature of the syndrome and providing a potential therapeutic inroad for the treatment of individuals with 3q29Del. Finally, we identify a high degree of social disability in female 3q29Del participants; the $3 \mathrm{q} 29$ deletion elevates the risk ASD in females $(\mathrm{OR}=$ $41.8, p=4.78 \mathrm{E}-05)$ more substantially than in males $(\mathrm{OR}=24.6, p=6.06 \mathrm{E}-09)$. These results demonstrate that there is a benefit to studying rare CNVs such as 3q29Del; studying a single genomic variant with large effect allows us to control for genetic etiology and unmask the mechanisms underlying the development of neuropsychiatric and neurodevelopmental disorders.

\section{Additional file}

\begin{abstract}
Additional file 1: Figure S1. SCQ scores split by ASD status, sex, and ASD status/sex. Figure S2. CBCL/ABCL withdrawn sub-scale scores split by genotype, sex, and ASD status. Figure S3. Geographic distribution of study participants with 3q29Del. Table S1. Questionnaire demographics for the medical questionnaire, SRS, SCQ, ASSQ, and CBCL/ABCL. Tables S2. and S3. Sensitivity analysis description and results for effect of 3q29Del self-registrants. Table S4. Comparison of scores on all four scales for 3q29Del versus control. Table S5. SRS score comparison stratified by ASD status and sex. Table S6. SCQ score comparison stratified by ASD status and sex. Table S7. CBCL/ABCL DSM-oriented sub-scale score comparison. Table S8. Contribution of congenital heart defects to phenotypes of interest. Table S9. Test for confounding factors contributing to symptomology questionnaire scores. Table S10. CBCL/ABCL Withdrawn sub-scale score comparison. Table S11. Heart defects present in study sample. Table S12. Comparison of 3q29 registry-leveraged and goldstandard phenotyping measures. Table S13. Comparison of $C B C / A B C L$ sub-scale scores between 3q29Del and 22q11.2 deletion. (DOCX 539 kb)
\end{abstract}

\section{Abbreviations}

3q29Del: 3q29 deletion syndrome; ABCL: Adult Behavior Checklist; ADHD: Attention deficit/hyperactivity disorder; ASD: Autism spectrum disorder; ASSQ: Autism Spectrum Screening Questionnaire; CBCL: Child Behavior Checklist; CNV: Copy number variation; DSM: Diagnostic and statistical manual; GDD: Global developmental delay; ID: Intellectual disability; MR: Mental retardation; SCQ: Social Communication Questionnaire; SMS: Smith-Magenis Syndrome; SRS: Social Responsiveness Scale; SZ: Schizophrenia; WS: Williams syndrome

\section{Acknowledgements}

We gratefully acknowledge our study population, the 3q29 deletion community, for their participation and commitment to research. This manuscript is currently available on the bioRxiv preprint server (https://doi. org/10.1101/386243).

We also acknowledge the contributions of the members of the Emory 3 q29 Project: Hallie Averbach, Emily Black, Gary J Bassell, T Lindsey Burrell, Grace Carlock, Tamara Caspary, Joseph F Cubells, David Cutler, Paul A Dawson, 
Roberto Espana, Michael J Gambello, Katrina Goines, Henry R Johnston, Sookyong Koh, Elizabeth J Leslie, Longchuan Li, Bryan Mak, Tamika Malone, Trenell Mosley, Derek Novacek, Ryan Purcell, Timothy Rutkowski, Rossana Sanchez, Jason Schroeder, Esra Sefik, Brittney Sholar, Sarah Shultz, Nikisha Sisodiya, Steven Sloan, Elaine F Walker, Stephen T Warren, David Weinshenker, Zhexing Wen, and Mike Zinsmeister.

\section{Authors' contributions}

RMP performed the statistical analysis, produced all figures and tables, and wrote the manuscript. MMM collected the data. MPE helped with statistical analyses and interpretation. MMM, CK, and CAS helped with data interpretation. MEZ and JGM edited the manuscript and provided guidance on analyzing and interpreting data. JGM was the principal investigator responsible for study direction. All authors participated in commenting on the drafts and have read and approved the final manuscript.

\section{Funding}

Funded by NIH 1R01MH110701-01A1 (Mulle), the Treasure Your Exceptions Project (Zwick), and NIH T32 GM0008490 (Pollak).

\section{Availability of data and materials}

The datasets used and analyzed during the current study are available from the corresponding author on reasonable request.

\section{Ethics approval and consent to participate}

This study was approved by Emory University's Institutional Review Board (IRB00064133). All study subjects gave informed consent prior to participating in this study.

\section{Consent for publication}

Not applicable.

\section{Competing interests}

CAS reports receiving royalties from Pearson Clinical for the Vineland-3. The other authors declare that they have no competing interests.

\section{Author details}

${ }^{1}$ Genetics and Molecular Biology, Laney Graduate School, Emory University, Atlanta, USA. ${ }^{2}$ Department of Human Genetics, School of Medicine, Emory University, Atlanta, USA. ${ }^{3}$ Department of Pediatrics, School of Medicine, Emory University, Atlanta, USA. ${ }^{4}$ Marcus Autism Center, Children's Healthcare of Atlanta and Emory University School of Medicine, Atlanta, USA. ${ }^{5}$ Department of Epidemiology, Rollins School of Public Health, Emory University, Atlanta, USA. ${ }^{6}$ Whitehead 305M, 615 Michael Street, Atlanta, GA 30322, USA.

\section{Received: 4 February 2019 Accepted: 20 June 2019}

\section{Published online: 16 July 2019}

\section{References}

1. Stefansson H, Meyer-Lindenberg A, Steinberg S, Magnusdottir B, Morgen K, Arnarsdottir S, Bjornsdottir G, Walters GB, Jonsdottir GA, Doyle OM, et al. CNVs conferring risk of autism or schizophrenia affect cognition in controls. Nature. 2014;505:361-6.

2. Kendall KM, Rees E, Escott-Price V, Einon M, Thomas R, Hewitt J, O'Donovan MC, Owen MJ, Walters JTR, Kirov G. Cognitive performance among carriers of pathogenic copy number variants: analysis of 152,000 UK biobank subjects. Biol Psychiatry. 2017;82:103-10.

3. Willatt L, Cox J, Barber J, Cabanas ED, Collins A, Donnai D, FitzPatrick DR, Maher E, Martin H, Parnau J, et al. 3929 microdeletion syndrome: clinical and molecular characterization of a new syndrome. Am J Hum Genet. 2005; 77:154-60.

4. Ballif BC, Theisen A, Coppinger J, Gowans GC, Hersh JH, Madan-Khetarpal S, Schmidt KR, Tervo R, Escobar LF, Friedrich CA, et al. Expanding the clinical phenotype of the $3 q 29$ microdeletion syndrome and characterization of the reciprocal microduplication. Mol Cytogenet. 2008;1:8.

5. Glassford MR, Rosenfeld JA, Freedman AA, Zwick ME, Mulle JG. Unique Rare Chromosome Disorder Support G: Novel features of 3q29 deletion syndrome: results from the 3q29 registry. Am J Med Genet Part A. 2016; 170A:999-1006.
6. Cobb W, Anderson A, Turner C, Hoffman RD, Schonberg S, Levin SW. 1.3 Mb de novo deletion in chromosome band 3q29 associated with normal intelligence in a child. Eur J Med Genet. 2010;53:415-8.

7. Mulle JG. The $3 \mathrm{q} 29$ deletion confers $>40$-fold increase in risk for schizophrenia. Mol Psychiatry. 2015;20:1028-9.

8. Mulle JG, Dodd AF, McGrath JA, Wolyniec PS, Mitchell AA, Shetty AC, Sobreira NL, Valle D, Rudd MK, Satten G, et al. Microdeletions of 3929 confer high risk for schizophrenia. Am J Hum Genet. 2010;87:229-36.

9. Marshall CR, Howrigan DP, Merico D, Thiruvahindrapuram B, Wu W, Greer DS, Antaki D, Shetty A, Holmans PA, Pinto D, et al. Contribution of copy number variants to schizophrenia from a genome-wide study of 41,321 subjects. Nat Genet. 2017;49:27-35.

10. Kirov G, Pocklington AJ, Holmans P, Ivanov D, Ikeda M, Ruderfer D, Moran J, Chambert K, Toncheva D, Georgieva L, et al. De novo CNV analysis implicates specific abnormalities of postsynaptic signalling complexes in the pathogenesis of schizophrenia. Mol Psychiatry. 2012;17:142-53.

11. Szatkiewicz JP, O'Dushlaine C, Chen G, Chambert K, Moran JL, Neale BM, Fromer M, Ruderfer D, Akterin S, Bergen SE, et al. Copy number variation in schizophrenia in Sweden. Mol Psychiatry. 2014;19:762.

12. Cox DM, Butler MG. A clinical case report and literature review of the $3 q 29$ microdeletion syndrome. Clin Dysmorphol. 2015;24:89-94.

13. Città S, Buono S, Greco D, Barone C, Alfei E, Bulgheroni S, Usilla A, Pantaleoni C, Romano C. 3q29 microdeletion syndrome: cognitive and behavioral phenotype in four patients. Am J Med Gene Part A. 2013;161A: 3018-22.

14. Sagar A, Bishop JR, Tessman DC, Guter S, Martin CL, Cook EH. Cooccurrence of autism, childhood psychosis, and intellectual disability associated with a de novo 3q29 microdeletion. Am J Med Genet Part A. 2013;161A:845-9.

15. Quintero-Rivera F, Sharifi-Hannauer P, Martinez-Agosto JA. Autistic and psychiatric findings associated with the 3q29 microdeletion syndrome: case report and review. Am J Med Gene Part A. 2010;152A:2459-67.

16. Biamino E, Di Gregorio E, Belligni EF, Keller R, Riberi E, Gandione M, Calcia A, Mancini C, Giorgio E, Cavalieri S, et al. A novel 3q29 deletion associated with autism, intellectual disability, psychiatric disorders, and obesity. Am J Med Genet Part B, Neuropsychiatr Genet. 2016;171B:290-9.

17. Itsara A, Cooper GM, Baker C, Girirajan S, Li J, Absher D, Krauss RM, Myers RM, Ridker PM, Chasman Dl, et al. Population analysis of large copy number variants and hotspots of human genetic disease. Am J Hum Genet. 2009;84:148-61.

18. Sanders SJ, He X, Willsey AJ, Ercan-Sencicek AG, Samocha KE, Cicek AE, Murtha MT, Bal VH, Bishop SL, Dong S, et al. Insights into autism spectrum disorder genomic architecture and biology from 71 risk loci. Neuron. 2015; 87:1215-33.

19. Schneider M, Debbané M, Bassett AS, Chow EWC, Fung WLA, van den Bree M, Owen M, Murphy KC, Niarchou M, Kates WR, et al. Psychiatric disorders from childhood to adulthood in 22q11.2 deletion syndrome: results from the International Consortium on Brain and Behavior in 22q11.2 Deletion Syndrome. Am J Psychiatry. 2014;171:627-39.

20. McDonald-McGinn DM, Sullivan KE, Marino B, Philip N, Swillen A, Vorstman $J A$, Zackai EH, Emanuel BS, Vermeesch JR, Morrow BE, et al. 22q11.2 deletion syndrome. Nat Rev Dis Primers. 2015;1:15071.

21. D'Angelo D, Lebon S, Chen Q, Martin-Brevet S, Snyder LG, Hippolyte L, Hanson E, Maillard AM, Faucett WA, Mace A, et al. Defining the effect of the 16p11.2 duplication on cognition, behavior, and medical comorbidities. JAMA Psychiatry. 2016;73:20-30.

22. Hanson E, Bernier R, Porche K, Jackson Fl, Goin-Kochel RP, Snyder LG, Snow AV, Wallace AS, Campe KL, Zhang Y, et al. The cognitive and behavioral phenotype of the 16p11.2 deletion in a clinically ascertained population. Biol Psychiatry. 2015;77:785-93.

23. Mervis CB, Klein-Tasman BP, Huffman MJ, Velleman SL, Pitts $C H$, Henderson DR, Woodruff-Borden J, Morris CA, Osborne LR. Children with 7q11.23 duplication syndrome: psychological characteristics. Am J Med Genet Part A. 2015;167:1436-50.

24. Brunetti-Pierri N, Berg JS, Scaglia F, Belmont J, Bacino CA, Sahoo T, Lalani SR, Graham B, Lee B, Shinawi M, et al. Recurrent reciprocal 1 q21. 1 deletions and duplications associated with microcephaly or macrocephaly and developmental and behavioral abnormalities. Nat Genet. 2008;40:1466-71.

25. Constantino JN, Todd RD. The social responsiveness scale manual. 2nd ed. Western Psychological Services: Los Angeles; 2012. 
26. Rutter M, Bailey A, Lord C. The Social Communication Questionnaire Manual. Western Psychological Services: Los Angeles; 2003.

27. Ehlers S, Gillberg C, Wing L. A screening questionnaire for Asperger syndrome and other high-functioning autism spectrum disorders in school age children. J Autism Dev Disord. 1999;29.

28. Achenbach TM, Rescorla LA. Manual for the ASEBA school-age forms \& profiles. Burlington, VT: University of Vermont, Research Center for Children, Youth and Families; 2001.

29. Achenbach TM, Rescorla LA. Manual for the ASEBA adult forms \& profiles. Burlington, VT: University of Vermont, Research Center for Children, Youth and Families; 2003.

30. R Core Team: R. A language and environment for statistical computing. Vienna, Austria: R Foundation for Statistical Computing; 2008.

31. Christensen RHB: Ordinal - Regression models for ordinal data. R package version 20156-28 2015

32. Nakazawa M: fmsb: functions for medical statistics book with some demographic data. R package version 0632018.

33. Sievert C, Parmer C, Hocking T, Chamberlain S, Ram K, Convellec M, Despouy P: plotly: create interactive web graphics via 'plotly.js'. R package version 4602017.

34. Wickham H. ggplot2: elegant graphics for data analysis. New York: SpringerVerlag; 2009.

35. Christensen DL, Braun KVN, Baio J, Bilder D, Charles J, Constantino JN, Daniels J, Durkin MS, Fitzgerald RT, Kurzius-Spencer $M$, et al. Prevalence and characteristics of autism spectrum disorder among children aged 8 years - Autism and Developmental Disabilities Monitoring Network, 11 sites, United States, 2012. MMWR Surveill Summ. 2018:65:1-23.

36. Zablotsky B, Black LI, Blumberg SJ. Estimated prevalence of children with diagnosed developmental disabilities in the United States, 2014-2016. NCHS Data Brief. 2017:1-8.

37. Kessler RC, Birnbaum H, Demler O, Falloon IR, Gagnon E, Guyer M, Howes MJ, Kendler KS, Shi L, Walters E, Wu EQ. The prevalence and correlates of nonaffective psychosis in the National Comorbidity Survey Replication (NCSR). Biol Psychiatry. 2005:58:668-76.

38. Wu EQ, Shi L, Birnbaum H, Hudson T, Kessler R. Annual prevalence of diagnosed schizophrenia in the USA: a claims data analysis approach. Psychol Med. 2006;36:1535-40.

39. Desai PR, Lawson KA, Barner JC, Rascati KL. Estimating the direct and indirect costs for community-dwelling patients with schizophrenia. J Pharm Health Serv Res. 2013;4:187-94.

40. Saha S, Chant D, Welham J, McGrath J. A systematic review of the prevalence of schizophrenia. PLoS Med. 2005;2:e141.

41. Moreno-Kustner B, Martin C, Pastor L. Prevalence of psychotic disorders and its association with methodological issues. A systematic review and metaanalyses. PLoS One. 2018;13:e0195687.

42. Merikangas KR, He JP, Burstein M, Swanson SA, Avenevoli S, Cui L, Benjet C, Georgiades K, Swendsen J. Lifetime prevalence of mental disorders in U.S. adolescents: results from the National Comorbidity Survey Replication--Adolescent Supplement (NCS-A). J Am Acad Child Adolesc Psychiatry. 2010;49:980-9.

43. Torske T, Naerland T, Oie MG, Stenberg N, Andreassen OA. Metacognitive aspects of executive function are highly associated with social functioning on parent-rated measures in children with autism spectrum disorder. Front Behav Neurosci. 2017;11:258.

44. Murphy MM, Lindsey Burrell T, Cubells JF, Espana RA, Gambello MJ, Goines KCB, Klaiman C, Li L, Novacek DM, Papetti A, et al. Study protocol for The Emory 3q29 Project: evaluation of neurodevelopmental, psychiatric, and medical symptoms in 3q29 deletion syndrome. BMC Psychiatry. 2018;18:183.

45. Rogers BT, Msali ME, Buck GM, Lyon NR, Norris MK, Roland JMA, Gingell RL, Cleveland DC, Pieroni DR. Neurodevelopmental outcome of infants with hypoplastic left heart syndrome. J Pediatr. 1995:496-8.

46. Forbess JM, Visconti KJ, Hancock-Friesen C, Howe RC, Bellinger DC, Jonas RA: Neurodevelopmental outcome after congenital heart surgery: results from an institutional registry. Circulation 2002, 106:--95-I-102.

47. Wernovsky G, Shillingford AJ, Gaynor JW. Central nervous system outcomes in children with complex congenital heart disease. Current Opinions in Cardiology. 2005:94-9.

48. Karsdorp PA, Everaerd W, Kindt M, Mulder BJ. Psychological and cognitive functioning in children and adolescents with congenital heart disease: a meta-analysis. J Pediatr Psychol. 2007;32:527-41.
49. Shillingford AJ, Glanzman MM, Ittenbach RF, Clancy RR, Gaynor JW, Wernovsky G. Inattention, hyperactivity, and school performance in a population of school-age children with complex congenital heart disease. Pediatrics. 2008;121:e759-67.

50. Kovacs AH, Saidi AS, Kuhl EA, Sears SF, Silversides C, Harrison JL, Ong L, Colman J, Oechslin E, Nolan RP. Depression and anxiety in adult congenital heart disease: predictors and prevalence. Int J Cardiol. 2009;137:158-64.

51. Bishop SL, Thurm A, Farmer C, Lord C. Autism spectrum disorder, intellectual disability, and delayed walking. Pediatrics. 2016;137:e20152959.

52. De Rubeis S, He X, Goldberg AP, Poultney CS, Samocha K, Cicek AE, Kou Y, Liu L, Fromer M, Walker S, et al. Synaptic, transcriptional and chromatin genes disrupted in autism. Nature. 2014;515:209-15.

53. Noterdaeme M, Minow F, Amorosa H. Applicability of the Child Behavior Checklist in developmentally delayed children. Z Kinder Jugendpsychiatr Psychother. 1999;27:183-8.

54. Mazefsky CA, Anderson R, Conner CM, Minshew N. Child Behavior Checklist scores for school-aged children with autism: preliminary evidence of patterns suggesting the need for referral. J Psychopatho Behav Assess. 2011;33:31-7.

55. Bruining $H$, Eijkemans MJ, Kas MJ, Curran SR, Vorstman JA, Bolton PF. Behavioral signatures related to genetic disorders in autism. Mol Autism. 2014;5:11.

56. Klein-Tasman BP, Mervis CB. Autism spectrum symptomatology among children with duplication 7q11.23 syndrome. J Autism Dev Disord. 2018;48: 1982-94.

57. Hidding $E$, Swaab $H$, de Sonneville LM, van Engeland $H$, Sijmens-Morcus ME, Klaassen PW, Duijff SN, Vorstman JA. Intellectual functioning in relation to autism and ADHD symptomatology in children and adolescents with 22q11.2 deletion syndrome. J Intellect Disabil Res. 2015;59:803-15.

58. Vorstman JA, Breetvelt EJ, Thode KI, Chow EW, Bassett AS. Expression of autism spectrum and schizophrenia in patients with a 22q11.2 deletion. Schizophr Res. 2013;143:55-9.

59. Vorstman JA, Morcus ME, Duijff SN, Klaassen PW, Heineman-de Boer JA, Beemer FA, Swaab H, Kahn RS, van Engeland H. The 22q11.2 deletion in children: high rate of autistic disorders and early onset of psychotic symptoms. J Am Acad Child Adolesc Psychiatry. 2006:45:1104-13.

60. Qiao Y, Riendeau N, Koochek M, Liu X, Harvard C, Hildebrand MJ, Holden JJ, Rajcan-Separovic E, Lewis ME. Phenomic determinants of genomic variation in autism spectrum disorders. J Med Genet. 2009;46:680-8.

61. Flor J, Bellando J, Lopez M, Shui A. Developmental functioning and medical Co-morbidity profile of children with complex and essential autism. Autism Res. 2017;10:1344-52.

62. Finlay WML, Lyons E. Methodological issues in interviewing and using selfreport questionnaires with people with mental retardation. Psychol Assess. 2001;13:319-35.

63. Fisher MH, Mello MP, Dykens EM. Who reports it best? A comparison between parent-report, self-report, and the real life social behaviors of adults with Williams syndrome. Res Dev Disabilities. 2014;35:3276-84.

64. Lincoln AJ, Searcy YM, Jones W, Lord C. Social interaction behaviors discriminate young children with autism and Williams syndrome. J Am Acad Child Adolesc Psychiatry. 2007:46:323-31.

65. Riby DM, Hanley M, Kirk H, Clark F, Little K, Fleck R, Janes E, Kelso L, O'Kane F, Cole-Fletcher $R$, et al. The interplay between anxiety and social functioning in Williams syndrome. J Autism Dev Disord. 2014;44:1220-9.

66. van der Fluit F, Gaffrey MS, Klein-Tasman BP. Social cognition in Williams syndrome: relations between performance on the social attribution task and cognitive and behavioral characteristics. Front Psychol. 2012;3:197.

67. Morris CA, Mervis CB, Paciorkowski AP, Abdul-Rahman O, Dugan SL, Rope AF, Bader P, Hendon LG, Velleman SL, Klein-Tasman BP, Osborne LR. 7q11.23 duplication syndrome: physical characteristics and natural history. Am J Med Genet A. 2015;167a:2916-35.

68. Sanders SJ, Ercan-Sencicek AG, Hus V, Luo R, Murtha MT, Moreno-De-Luca D, Chu SH, Moreau MP, Gupta AR, Thomson SA, et al. Multiple recurrent de novo CNVs, including duplications of the 7q11.23 Williams syndrome region, are strongly associated with autism. Neuron. 2011;70:863-85.

69. Niarchou M, Chawner S, Doherty JL, Maillard AM, Jacquemont S, Chung WK, Green-Snyder L, Bernier RA, Goin-Kochel RP, Hanson E, et al. Psychiatric disorders in children with 16p11.2 deletion and duplication. Transl Psychiatry. 2019;9:8.

70. Zufferey F, Sherr EH, Beckmann ND, Hanson E, Maillard AM, Hippolyte L, Macé A, Ferrari C, Kutalik Z, Andrieux J, et al. A 600 kb deletion syndrome at 
16p11.2 leads to energy imbalance and neuropsychiatric disorders. J Med Genet. 2012;49:660-8.

71. Green Snyder L, D'Angelo D, Chen Q, Bernier R, Goin-Kochel RP, Wallace AS, Gerdts J, Kanne S, Berry L, Blaskey L, et al. Autism spectrum disorder, developmental and psychiatric features in 16p11.2 duplication. J Autism Dev Disord. 2016;46:2734-48.

72. Nag HE, Nordgren A, Anderlid BM, Nærland T. Reversed gender ratio of autism spectrum disorder in Smith-Magenis syndrome. Mol Autism. 2018;9:1.

73. Schreiner MJ, Karlsgodt KH, Uddin LQ, Chow C, Congdon E, Jalbrzikowski M, Bearden CE. Default mode network connectivity and reciprocal social behavior in 22q11.2 deletion syndrome. Soc Cogn Affect Neurosci. 2014;9: 1261-7.

74. Niklasson L, Rasmussen P, Oskarsdottir S, Gillberg C. Autism, ADHD, mental retardation and behavior problems in 100 individuals with 22q11 deletion syndrome. Res Dev Disabil. 2009;30:763-73.

75. Sobin C, Kiley-Brabeck K, Monk SH, Khuri J, Karayiorgou M. Sex differences in the behavior of children with the 22q11 deletion syndrome. Psychiatry Res. 2009;166:24-34

\section{Publisher's Note}

Springer Nature remains neutral with regard to jurisdictional claims in published maps and institutional affiliations.

Ready to submit your research? Choose BMC and benefit from:

- fast, convenient online submission

- thorough peer review by experienced researchers in your field

- rapid publication on acceptance

- support for research data, including large and complex data types

- gold Open Access which fosters wider collaboration and increased citations

- maximum visibility for your research: over $100 \mathrm{M}$ website views per year

At BMC, research is always in progress.

Learn more biomedcentral.com/submissions 